\title{
(6) OPEN ACCESS \\ The impact of low-dose glucocorticoids on disease activity, bone mineral density, fragility fractures, and 10-year probability of fractures in patients with rheumatoid arthritis
}

\author{
Tien-Tsai Cheng, ${ }^{1,2}$ Han-Ming Lai, ${ }^{1}$ Shan-Fu Yu, ${ }^{1,2}$ Wen-Chan Chiu, ${ }^{1}$ \\ Chung-Yuan Hsu, ${ }^{1}$ Jia-Feng Chen, ${ }^{1}$ Ying-Chou Chen ${ }^{1,2}$
}

${ }^{1}$ Kaohsiung Chang Gung Memorial Hospital, Kaohsiung, Taiwan ${ }^{2}$ Chang Gung University College of Medicine, Kaohsiung, Taiwan

\section{Correspondence to} Dr Ying-Chou Chen, Department of Rheumatology, Kaohsiung Chang Gung Memorial Hospital, Chang Gung University College of Medicine, Kaohsiung 833, Taiwan;

r820713@ms13.hinet.net

Accepted 2 May 2018

Check for updates

To cite: Cheng T-T, Lai H-M, Yu S-F, et al. J Investig Med 2018:66:1004-1007.

\section{ABSTRACT}

This study aimed to investigate the effect of lowdose glucocorticoids (LDGs) on disease activity, bone density, and fractures in patients with rheumatoid arthritis (RA). This was an interim analysis of the RA Registry. Demographic data and clinical characteristics, including fracture risk assessment tool, were collected. 25(OH) Vitamin D, bone mineral density (BMD), and intact parathyroid hormone were measured at enrollment. The study group were those who took LDGs (2.5-7.5 mg/ day prednisolone or equivalent dose), and the others were included as the control group. A total of 425 participants were enrolled, including 85 $(20 \%)$ in the control group and $340(80 \%)$ in the study group. The demographics and clinical characteristics were comparable between the two groups. Compared with the control group, the LDGs group had a significantly lower vertebral BMD (L 1-4) $\left(\mathrm{g} / \mathrm{cm}^{2}\right)$, (0.854 vs $\left.0.896, \mathrm{p}=0.046\right)$, significantly higher rate of previous fractures (103 $(30.3 \%)$ vs $13(15.3 \%), p=0.006)$, higher 10 -year probability of major fractures (14 (15.5) vs 8 (8.6), $p<0.0001)$, and higher 10 -year probability of hip fractures (4.4 (8.4) vs 2 (3.9), $p<0.0001)$. Disease activity appeared to be similar in the patients with RA regardless of whether or not they received LDG treatment. However, the patients with RA who received $L D G$ treatment had a lower $B M D$ at the spine (L1-4) and a higher rate of previous fractures that was associated with a significantly higher 10year probability of fractures than those who did not receive LDG treatment.

\section{INTRODUCTION}

Rheumatoid arthritis (RA) is often treated with glucocorticoids (GCs). ${ }^{1}$ GC therapy is considered to have association with the risk of fractures ${ }^{2}$ and the rapid reduction in the bone mineral density (BMD), especially of the trabecular bone. It is reported that after 5-7 months of GC therapy, 25\% of them had loss of trabecular bone. ${ }^{3}$ Besides, among the patients with secondary osteoporosis, GC treatment is the most common, ${ }^{1}$ which leads to increase in the risk of fractures. Van Staa

\section{Significance of this study}

What is already known about this subject?

- Rheumatoid arthritis (RA) is often treated with glucocorticoids (GCs).

- GC therapy had impact on risk of fractures and low bone mineral density (BMD), especially of the trabecular bone.

What are the new findings?

- Lower BMD at the spine (L1-4) and a higher rate of previous fractures in patients with chronic RA who received low-dose glucocorticoid (LDG) treatment that was associated with a significantly higher 10year probability of fractures than those who did not receive LDG treatment.

How might these results change the focus of research or clinical practice?

- It is mandatory to carefully assess and detect fractures in patients with RA who receive chronic GC therapy.

- We recommend that physicians should assess and determine the risk of fractures in patients with RA who receive chronic $\mathrm{GC}$ therapy.

et $a l^{4}$ reported a twofold increased risk of fractures in postmenopausal women taking GCs.

Previous studies have identified the factors that contribute to the risk of fractures. The WHO then approved the development of aflow chart for risk assessment that can be used in primary care settings, and when BMD is not available. So, the fracture risk assessment tool (FRAX) was developed, which can be used to assess 10-year probability of major osteoporotic fracture (clinical spine, forearm, hip, or shoulder) and a hip fracture in both men and women. ${ }^{56}$ GC therapy for RA leads to fractures and impacts mortality, ${ }^{78}$ the patient's quality-of-life (including physical functioning), ${ }^{9}{ }^{10}$ and the risk of future fractures. ${ }^{11}$ 
A few studies have investigated the effect of chronic GC therapy on osteoporosis in patients with RA.

The primary objective of this study was to determine the BMD in these patients, and the secondary objective was to determine the risk of fractures (major and minor).

\section{MATERIALS AND METHODS}

This was an interim analysis of the RA Registry conducted at Chang Gung Memorial Hospital in Kaohsiung (CGMHK). All participants provided written informed consent.

In the Registry, consecutive RA study subjects who visited Rheumatology Clinic at CGMHK from September 1, 2014 to September 2017 and fulfilled classification criteria for RA were enrolled. ${ }^{12}$

The demographic data and clinical characteristics, including lifestyle, including diet, evidence of previous fragility fracture, and risk factors for fracture in FRAX, were collected. Anti-citrullinated protein antibodies (anti-CCP), rheumatoid factor (RF), erythrocyte sedimentation rate (ESR), disease activity-28 joint-erythrocyte sedimentation rate score (DAS28-ESR), C reactive protein (CRP), 25 $(\mathrm{OH})$ Vitamin D, intact parathyroid hormone, and BMD weres measured at enrollment.

Those on low-dose glucocorticoid (LDG, $2.5-7.5 \mathrm{mg} /$ day prednisolone or equivalent dose) were included as the study group and the others were included as the control group. Those with GC intake of more than $7.5 \mathrm{mg} /$ day were excluded. We calculated the 10-year probabilities of major and hip fractures using the Taiwanese-specific FRAX. Participants were categorized into low-risk, medium-risk, and high-risk groups for major osteoporotic fracture based on the 10-year fracture risk probability calculated using FRAX with cut-off points of $10 \%$ and $20 \% .{ }^{13}$ We followed the guidance of the International Osteoporosis Fundation (IOF)/European Calcified Tissue Society (ECTS) for glucocorticoid induced osteoporosis (GIOP) to calculate the intervention threshold for each participant. ${ }^{14}$ We modified the calculation of individual intervention threshold (IIT) by inputting gender, body weight, and body height and assumed that the participant had a 'prior fracture' but no other risk factors and BMD unavailable. ${ }^{15}$ Then, we recalculated the individual-specific 10 -year probability of major fracture of that participant by inputting the real situation. We defined 'above IIT' as 10-year probability of major fracture of that participant being higher or equal to IIT of the same participant. We compared the proportion of the above IIT between the GC users and controls. ${ }^{15}$

\section{RESULTS}

There were a total of 425 study subjects. There were 85 (20\%) who never used corticosteroids (control group) and 340 (80\%) who accepted LDG (study group). The age, $\mathrm{BMD}$, disease duration, symptoms of RA to diagnosis of RA, habit (tea and coffee), proportion of vegetarian, anti-CCP, RF, ESR, CRP, DAS28, and vitamin D level were the same for both groups. The demographics and clinical characteristics were comparable between the groups. Compared with control group subjects, study subjects on LDG had a significantly lower vertebral BMD (L 1-4) $\left(\mathrm{g} / \mathrm{cm}^{2}\right),(0.854(0.200)$ vs $0.896(0.201), p=0.046)$ and a higher rate of previous
Table 1 Participants' demographics and clinical characteristics

\begin{tabular}{|c|c|c|c|c|}
\hline Variables* & $\begin{array}{l}\text { All } \\
n=425\end{array}$ & $\begin{array}{l}\text { LDG (-) } \\
\mathrm{n}=85\end{array}$ & $\begin{array}{l}\text { LDG (+) } \\
\mathrm{n}=340\end{array}$ & $P$ values \\
\hline Age (years) & $57(14)$ & $58(14)$ & $57(14)$ & 0.9107 \\
\hline Female, $\mathrm{n}(\%)$ & $375(88.2)$ & $75(88.2)$ & $300(88.2)$ & 1 \\
\hline BMI $\left(\mathrm{kg} / \mathrm{m}^{2}\right)$ & $23.4(5.0)$ & $23.4(4.7)$ & $23.4(5.0)$ & 0.916 \\
\hline Disease duration (years) & $\begin{array}{l}10(13) \\
n=408\end{array}$ & $\begin{array}{l}12(13) \\
n=83\end{array}$ & $\begin{array}{l}10(13) \\
n=325\end{array}$ & 0.478 \\
\hline Symptom to diagnosis (years) & $\begin{array}{l}2(5) \\
n=408\end{array}$ & $\begin{array}{l}1(4) \\
n=83\end{array}$ & $\begin{array}{l}2(5) \\
n=325\end{array}$ & 0.336 \\
\hline Teat, n (\%) & $81(19.1)$ & $17(20.0)$ & $64(18.8)$ & 0.805 \\
\hline Coffeet, $\mathrm{n}(\%)$ & $79(18.6)$ & $19(22.4)$ & $60(17.6)$ & 0.319 \\
\hline Vegetarian $\neq, \mathrm{n}(\%)$ & $23(5.4)$ & $5(5.9)$ & $18(5.3)$ & 0.791 \\
\hline Anti-CCP ( $\geq 7 \mathrm{U} / \mathrm{mL}), \mathrm{n}(\%)$ & $\begin{array}{l}287(69.3) \\
n=414\end{array}$ & $\begin{array}{l}51(61.4) \\
n=83\end{array}$ & $\begin{array}{l}236(71.3) \\
n=331\end{array}$ & 0.082 \\
\hline $\mathrm{RF}(\geq 15 \mathrm{U} / \mathrm{mL}), \mathrm{n}(\%)$ & $\begin{array}{l}284(67.5) \\
n=421\end{array}$ & $\begin{array}{l}57(67.1) \\
\mathrm{n}=85\end{array}$ & $\begin{array}{l}227(67.6) \\
n=336\end{array}$ & 0.930 \\
\hline ESR (mm/hour) & $16(20)$ & 14 (18) & $17(21)$ & 0.426 \\
\hline $\mathrm{CRP}$ (mg/L) & $2.8(6.7)$ & $1.9(4.2)$ & $3(7.4)$ & 0.299 \\
\hline DAS28-ESR & $\begin{array}{l}3.2(1.6) \\
n=422\end{array}$ & $\begin{array}{l}2.9(1.7) \\
n=84\end{array}$ & $\begin{array}{l}3.3(1.6) \\
n=338\end{array}$ & 0.107 \\
\hline iPTH $(\mathrm{pg} / \mathrm{mL})$ & $57(14)$ & $41.3(23.3)$ & $39.9(28.2)$ & 0.454 \\
\hline Vitamin D 25(OH) $(\mathrm{ng} / \mathrm{mL})$ & $\begin{array}{l}20.9(9.3) \\
n=332\end{array}$ & $\begin{array}{l}22.0(8.6) \\
n=71\end{array}$ & $\begin{array}{l}20.8(10.0) \\
n=261\end{array}$ & 0.679 \\
\hline Comorbidity, n (\%) & $238(56)$ & $41(48.2)$ & $197(57.9)$ & 0.107 \\
\hline bDMARD, n (\%) & $74(17.4)$ & $20(23.5)$ & $54(15.9)$ & 0.096 \\
\hline Osteoporosisף, n (\%) & $\begin{array}{l}109(27.3) \\
n=400\end{array}$ & $\begin{array}{l}18(22.2) \\
\mathrm{n}=81\end{array}$ & $\begin{array}{l}91(28.5) \\
n=319\end{array}$ & 0.2551 \\
\hline Current treatment ${ }^{* *}, \mathrm{n}(\%)$ & $62(14.6)$ & $6(7.1)$ & $56(16.5)$ & 0.028 \\
\hline Fall in previous year, $\mathrm{n}(\%)$ & $\begin{array}{l}67(16.4) \\
\mathrm{n}=409\end{array}$ & $\begin{array}{l}11(13.3) \\
\mathrm{n}=83\end{array}$ & $\begin{array}{l}56(17.2) \\
n=326\end{array}$ & 0.388 \\
\hline Fracture, n (\%) & $116(27.3)$ & $13(15.3)$ & $103(30.3)$ & 0.006 \\
\hline
\end{tabular}

${ }^{*}$ All data are expressed as median (IQR).

$\dagger$, regular daily drinker; $\ddagger$, more than 3 years; $\emptyset$, femoral neck T-score $\leq-2.5$; **, receiving antiosteoporosis therapy; $\mathrm{n}$, data available.

Anti-CCP, anti-citrullinated protein antibodies; bDMARDs, biologic diseasemodifying antirheumatic drugs; $\mathrm{BMD}$, bone mineral density; $\mathrm{BMI}$, body mass index; CRP, C reactive protein; DAS28-ESR, disease activity score- 28 joint-erythrocyte sedimentation rate; ESR, erythrocyte sedimentation rate; $\mathrm{PPTH}$, intact parathyroid hormone; LDG, low-dose glucocorticoid; RF, rheumatoid factor.

fracture (103 (30.3) vs 13 (15.3), $\mathrm{p}=0.006)$ (table 1$)$. The 10 -year probabilities (with BMD (without BMD)) of major $(14(15.5)$ vs $8(8.6), \mathrm{p}<0.0001)$ and hip $(4.4(8.4)$ vs 2 $(3.9), \mathrm{p}<0.0001)$ fractures, respectively, were higher in LDG group (table 2).

\section{DISCUSSION}

Higher 10-year risk of major osteoporotic fracture or hip fracture was found in patients who received LDG compared with patients who did not receive steroid treatment, as determined by FRAX analysis. In addition, the 10-year risk of fractures in low-dose steroid treatment patients appeared to be particularly high. LDG has been associated with an increased risk of fractures, ${ }^{16}{ }^{17}$ and GC administration has been reported to be a cause of secondary osteoporosis. ${ }^{1}$ Angeli $e t a l^{18}$ found that RA may increase the risk of fractures, and Van Staa et $a l^{19}$ revealed that a combination of RA activity and GC therapy contributes to an increased risk of fractures. However, it is difficult to evaluate the risk of fractures with LDG therapy. In our study, chronic LDG treatment was associated with a higher risk of fractures. FRAX is mandatory because this method only includes data 
Table 2 Comparison of the difference of BMD and FRAX of low-dose steroid group or those without low-dose steroid group

\begin{tabular}{|c|c|c|c|c|}
\hline & $\begin{array}{l}\text { All } \\
n=425\end{array}$ & $\begin{array}{l}\text { LDG (-) } \\
\mathrm{n}=85\end{array}$ & $\begin{array}{l}\text { LDG (+) } \\
\mathrm{n}=340\end{array}$ & $P$ values \\
\hline \multicolumn{5}{|l|}{ BMD $\left(\mathrm{g} / \mathrm{cm}^{2}\right)$} \\
\hline $\mathrm{FN}^{\mathrm{c}}$ & $\begin{array}{l}0.629(0.137) \\
n=400\end{array}$ & $\begin{array}{l}0.636(0.131) \\
n=81\end{array}$ & $\begin{array}{l}0.627(0.141) \\
n=319\end{array}$ & 0.314 \\
\hline Hip (total) & $\begin{array}{l}0.785(0.180) \\
n=400\end{array}$ & $\begin{array}{l}0.779(0.176) \\
n=81\end{array}$ & $\begin{array}{l}0.786(0.181) \\
n=319\end{array}$ & 0.731 \\
\hline L1-4 & $\begin{array}{l}0.865(0.197) \\
n=403\end{array}$ & $\begin{array}{l}0.896(0.201) \\
n=82\end{array}$ & $\begin{array}{l}0.854(0.200) \\
n=321\end{array}$ & 0.046 \\
\hline Fracture, n (\%) & $116(27.3)$ & $13(15.3)$ & $103(30.3)$ & 0.006 \\
\hline $\begin{array}{l}\text { FRAX (major, } \\
\text { with BMD) }\end{array}$ & $\begin{array}{l}12.5(14.3) \\
n=400\end{array}$ & $\begin{array}{l}8(8.6) \\
n=81\end{array}$ & $\begin{array}{l}14(15.5) \\
n=319\end{array}$ & $<0.0001$ \\
\hline $\begin{array}{l}\text { FRAX (hip, with } \\
\text { BMD) }\end{array}$ & $\begin{array}{l}3.5(7.2) \\
n=400\end{array}$ & $\begin{array}{l}2(3.9) \\
n=81\end{array}$ & $\begin{array}{l}4.4(8.4) \\
n=319\end{array}$ & $<0.0001$ \\
\hline $\begin{array}{l}\text { FRAX (major, } \\
\text { no BMD) }\end{array}$ & $11(14.3)$ & $7.1(7.4)$ & $12(15.7)$ & $<0.0001$ \\
\hline $\begin{array}{l}\text { FRAX (hip, } \\
\text { no BMD) }\end{array}$ & $3.2(6.8)$ & $1.6(3.5)$ & $3.6(8.3)$ & $<0.0001$ \\
\hline FRAX (major, IT) & $9.7(9.1)$ & $9.6(8.3)$ & $9.7(9.0)$ & 0.4556 \\
\hline FRAX (hip, IT) & $2.5(4.4)$ & $2.3(4.1)$ & $2.6(4.4)$ & 0.4255 \\
\hline
\end{tabular}

$B M D$, bone mineral density; FN, femoral neck; FRAX, fracture risk assessment tool; IT, intervention threshold; LDG , low -dose glucocorticoid.

on whether or not the patient uses steroids and does not consider the impact of the cumulative GC dose on the risk of fractures. Hence, the fracture risk prediction according to FRAX may be augmented by including the chronicity and dosage of GC therapy. Therefore, the links between chronicity and dosage of GC therapy can lead to increased risk of fractures. ${ }^{20}$

The reason why GC therapy increases the risk of fractures may be because GC therapy reduces $\mathrm{BMD}^{21} 22$ and also decreases bone quality through microarchitectural changes. ${ }^{22}$ Thus, prophylactic treatment may improve bone quality as well as quantity.

The FRAX estimates the risk of fractures by clinical risk factors. The methods can be used alone or with BMD to improve the prediction of fracture risk. Several previous reports have developed methods to predict fracture risk by combining clinical risk factors and $\mathrm{BMD},{ }^{23-25}$ with risk factors including activities of daily living, liability to falls, impaired cognition, poor overall health, history of stroke, seizure disorder, and several different medications.

The particular feature of the FRAX is that it takes into account risk factors from RA and previous osteoporotic fractures. ${ }^{26}{ }^{27}$ So, smoking, low BMD, and RA are risk factors for fractures. Therefore, at low T-scores, the risk of hip fractures lowers with age, in part due to the higher fractures associated with lower BMD values.

There are several limitations to this study. First, self-reported data contribute to all of the fractures. Second, a higher proportion of the patients were receiving medications to reduce the risk of fractures, and it may be regarded as a limitation when determining the prevalence of fractures in patients with RA. Third, a non-response bias may have impact on the results. It may lead to underestimation of absolute fracture risk. The analyses also have significant limitations that relate to risk factors and the outcome variables. The reason for which was an osteoporotic fracture which was not the same in all subjects, and the effects of this inconsistency are possibly to weaken the relationships that were found. Further problems lead to the questions to assess the presence or absence of risk factors, which varied between cohorts. These included questions on family history, prior fracture, smoking, and GC use. Recall bias and the validity of self-reported alcohol intake that are notoriously unreliable are particularly problematic in the elderly. Moreover, this was a single-center study. These limitations restrict the generalizability of the results. Nevertheless, this study has several strengths, including a large sample size relative to comparable studies. This approach is likely to have improved the accuracy to estimate the risk of fractures, to allow for more precise determination of the impact on patients' physical functioning.

\section{CONCLUSIONS}

We reported a relatively higher proportion of fractures in patients with RA receiving LDG. Our data also revealed that chronic GC therapy leads to non-vertebral fractures. Nevertheless, the risk of sustaining a fracture by the impact of cumulative GC is inconclusive. Besides, fractures had a negative effect on further fractures in a 10 -year period. To care for patients with RA who receive chronic GC therapy, it is particularly important to carefully monitor to detect fractures. Also, we recommend to take preventative measures in patients with RA on chronic GC therapy to decrease the risk of fractures.

Contributors T-TC and H-ML designed and performed the research. S-FY, W-CC, C-YH, and J-FC performed rheumatoid arthritis care. T-TC and Y-CC wrote the final paper.

Funding This study was supported by Kaohsiung Chang Gung Memorial Hospital and Chang Gung University College of Medicine, Kaohsiung grant. CMRPG8E1221.

Competing interests None declared.

Patient consent Obtained.

Ethics approval This retrospective study was approved by the institutional review board of Chang Gung Memorial Hospital.

Provenance and peer review Not commissioned; externally peer reviewed.

Open access This is an open access article distributed in accordance with the terms of the Creative Commons Attribution (CC BY 4.0) license, which permits others to distribute, remix, adapt and build upon this work, for commercial use, provided the original work is properly cited. See: http:// creativecommons.org/licenses/by/4.0/

(C) American Federation for Medical Research (unless otherwise stated in the text of the article) 2018. All rights reserved. No commercial use is permitted unless otherwise expressly granted.

\section{REFERENCES}

1 Nilsson IL, Norenstedt S, Zedenius J, et al. Primary hyperparathyroidism, hypercalciuria, and bone recovery after parathyroidectomy. Surgery 2017;162:429-36.

2 Helling TS, Daon E. The historic lethality of penetrating wounds to the hip. Surgery 1997;121:264-77.

3 Bailey PV, Weber TR, Tracy TF, et al. Congenital hemangiopericytoma: an unusual vascular neoplasm of infancy. Surgery 1993;114:936-41.

4 Bergqvist D, Kettunen K, Fredin H, et al. Thromboprophylaxis in patients with hip fractures: a prospective, randomized, comparative study between Org 10172 and dextran 70. Surgery 1991;109:617-22.

5 McCloskey EV, Johansson $\mathrm{H}$, Oden A, et al. From relative risk to absolute fracture risk calculation: the FRAX algorithm. Curr Osteoporos Rep 2009;7:77-83.

6 Kanis JA, Hans D, Cooper C, et al. Interpretation and use of FRAX in clinical practice. Osteoporos Int 2011;22:2395-411. 
7 Ioannidis G, Papaioannou A, Hopman WM, et al. Relation between fractures and mortality: results from the Canadian Multicentre Osteoporosis Study. CMAJ 2009;181:265-71.

8 Chen YC, Su FM, Cheng TT, et al. Can antiosteoporotic therapy reduce mortality in MRI-proved acute osteoporotic vertebral fractures? J Bone Miner Metab 2016;34:325-30.

9 Haukipuro K, Risteli L, Kairaluoma MI, et al. Aminoterminal propeptide of type III procollagen in serum during wound healing in human beings. Surgery 1990;107:381-8

10 Comerota AJ, Stewart GJ, Alburger PD, et al. Operative venodilation: a previously unsuspected factor in the cause of postoperative deep vein thrombosis. Surgery 1989;106:301-8.

11 Solomon RA, Viernstein MC, Long DM. Reduction of postoperative pain and narcotic use by transcutaneous electrical nerve stimulation. Surgery 1980;87:142-6.

12 Arnett FC, Edworthy SM, Bloch DA, et al. The American Rheumatism Association 1987 revised criteria for the classification of rheumatoid arthritis. Arthritis Rheum 1988;31:315-24.

13 Cosman F, de Beur SJ, LeBoff MS, et al. Clinician's guide to prevention and treatment of osteoporosis. Osteoporos Int 2014;25:2359-81.

14 Lekamwasam S, Adachi JD, Agnusdei D, et al. A framework for the development of guidelines for the management of glucocorticoid-induced osteoporosis. Osteoporos Int 2012;23:2257-76.

15 Yu SF, Chen JF, Chen YC, et al. Beyond bone mineral density, FRAX-based tailor-made intervention thresholds for therapeutic decision in subjects on glucocorticoid: A nationwide osteoporosis survey. Medicine 2017;96:e5959.

16 Zheng $\mathrm{F}$, Zhou $\mathrm{H}$, Li N, et al. Skeletal effects of failed parathyroidectomy. Surgery 2018;163:17-21.

17 Zhou Y, Cao S, Li L, et al. Is soft tissue repair a right choice to avoid early dislocation after THA in posterior approach? BMC Surg 2017;17:60.
18 Zheng Z, Yang L, Su Y, et al. Application of intraoperative limb-length measurement by a new osteotomy device in hemiarthroplasty for treating femoral neck fracture. BMC Surg 2017;17:57.

19 Silva AM, Vodopivec D, Christakis I, et al. Operative intervention for primary hyperparathyroidism offers greater bone recovery in patients with sporadic disease than in those with multiple endocrine neoplasia type 1-related hyperparathyroidism. Surgery 2017;161:107-15.

20 Liu R, Liang J, Wang K, et al. Sciatic nerve course in adult patients with unilateral developmental dysplasia of the hip: implications for hip surgery. BMC Surg 2015;15:14.

21 Hopmans CJ, den Hoed PT, van der Laan L, et al. Assessment of surgery residents' operative skills in the operating theater using a modified Objective Structured Assessment of Technical Skills (OSATS): a prospective multicenter study. Surgery 2014;156:1078-88.

22 Lundgren $\mathrm{E}$, Ljunghall S, Akerström G, et al. Case-control study on symptoms and signs of "asymptomatic" primary hyperparathyroidism. Surgery 1998;124:980-6.

23 Black DM, Steinbuch M, Palermo L, et al. An assessment tool for predicting fracture risk in postmenopausal women. Osteoporos Int 2001;12:519-28.

24 Burger $\mathrm{H}$, de Laet $\mathrm{CE}$, Weel $\mathrm{AE}$, et al. Added value of bone mineral density in hip fracture risk scores. Bone 1999;25:369-74.

25 Albrand G, Munoz F, Sornay-Rendu E, et al. Independent predictors of all osteoporosis-related fractures in healthy postmenopausal women: the OFELY study. Bone 2003;32:78-85.

26 Conroy RM, Pyörälä K, Fitzgerald AP, et al. Estimation of ten-year risk of fatal cardiovascular disease in Europe: the SCORE project. Eur Heart $\mathrm{J}$ 2003;24:987-1003.

27 Stevens RJ, Kothari V, Adler Al, et al. The UKPDS risk engine: a model for the risk of coronary heart disease in Type II diabetes (UKPDS 56). Clin Sci 2001;101:671-9. 